\title{
ORIGINAL ARTICLE \\ Assessment of genotoxicity and antigenotoxicity of an aqueous extract of Cleistocalyx nervosum var. paniala in in vitro and in vivo models
}

\author{
Suphachai CHAROENSIN 1,3*, Sirinya TAYA ${ }^{1 *}$, Sugunya WONGPORNCHAI ${ }^{2}$, Rawiwan WONGPOOMCHAI ${ }^{1}$ \\ 1 Department of Biochemistry, Faculty of Medicine, Chiang Mai University, Chiang Mai, Thailand \\ 2 Department of Chemistry, Faculty of Science, Chiang Mai University, Chiang Mai, Thailand \\ 3 Department of Biochemistry, School of Medical Science, University of Phayao, Phayao, Thailand \\ * These authors contributed equally to this work.
}

ITX050412A06 • Received:13 October 2012 • Revised: 10 December 2012 • Accepted: 26 December 2012

\begin{abstract}
Cleistocalyx nervosum var. paniala, an edible fruit found in Northern Thailand, contains high amounts of phenolic compounds with in vitro antioxidant activity. The aqueous extract of the ripe fruit was evaluated for its safety and beneficial effects using genotoxicity and toxicity tests. The C. nervosum extract was not only non-mutagenic in Salmonella typhimurium strains TA98 and TA100 in the presence and absence of metabolic activation, but exhibited also moderate antimutagenic effects against aflatoxin B1 and 2-amino3,4-dimethylimidazo[4,5-f]quinoline-induced mutagenesis. Electrospray ionization-mass spectrometric analysis revealed the major anthocyanins, which included cyanidin-3,5-diglucoside, cyanidin-3-glucoside and cyanidin-5-glucoside. The administration of $C$. nervosum at concentration of $5,000 \mathrm{mg} / \mathrm{kg}$ bw did not induce acute toxicity in rats. A liver micronucleus test was performed to detect clastogenicity and anticlastogenicity. The extract in the dose of $1,000 \mathrm{mg} / \mathrm{kg}$ did not cause micronucleus formation in the liver of rats. Furthermore, in rats administered $100-1,000 \mathrm{mg} / \mathrm{kg}$ of the extract, no anticlastogenic effect against diethylnitrosamine-induced hepatic micronucleus formation was observed. These studies provide data concerning the safety and antimutagenic potency of an aqueous extract of C. nervosum fruit.
\end{abstract}

KEY WORDS: Cleistocalyx nervosum var. paniala, acute toxicity, ames test, liver micronucleus assay

\section{Introduction}

Anthocyanins occur ubiquitously in flowering plants and confer the bright red, blue and purple colors to fruits and vegetables. Epidemiological studies have suggested that the consumption of anthocyanins lowers the risk of cardiovascular disease, diabetes, arthritis and cancer, due at least in part to anti-oxidant and anti-inflammatory activities (Prior \& Wu, 2006). Potential cancer chemopreventive activities of anthocyanins revealed in in vitro studies included radical scavenging activity, stimulation

Correspondence address: Rawiwan Wongpoomchai

Department of Biochemistry, Faculty of Medicine,

Chiang Mai University, Chiang Mai 50200, Thailand.

TEL.: +66 53945225 • FAX +66 53894031

E-MAlL: rpuatana@med.cmu.ac.th of phase II detoxifying enzymes, reduced cell proliferation, inflammation, angiogenesis, invasiveness and induction of apoptosis and differentiation (Caillet et al., 2012; Galvano et al., 2004). Anthocyanins were shown to exhibit anticarcinogenic activity against multiple cancer cell types in vitro and tumor types in vivo (Galvano et al., 2004; Stoner et al., 2008).

Cleistocalyx nervosum var. paniala family Myrtaceae is a native plant found in Northern Thailand, with an orange-red fruit that is commonly consumed either as fresh fruit or is used in fruit products. Previous studies have reported that cyanidin-3-glucosides were found in the ripe fruit of C. nervosum (Jansom et al., 2008). There are but few data concerning the biological activity of $C$. nervosum fruit in vitro or in vivo, though Cleistocalyx operculatus, which belongs to the same genus, has been investigated for its biological activities. The buds of $C$. 
operculatus are used in various beverages in Southern China (Ye et al., 2004a). Dung et al. studied the chemical composition, antimicrobial and antioxidant activities of the essential oil and ethanol extract of C. operculatus buds. 2',4'-Dihydroxy-6'-methoxy-3',5'-dimethylchalcone (DMC), isolated from buds of C. operculatus, was found to inhibit significantly the growth of human liver cancer SMMC-7721 cells (Ye et al., 2004b; Dung et al., 2008).

In studies of natural products, it is quite common to characterize their benefits and hazards to humans through extrapolation of effects from in vitro and animal studies. The goal of mutagenicity testing is to identify genotoxic or carcinogenic effects of the test compound (Rao et al., 2004). The standard short-term genotoxicity tests include bacterial mutation assays (Ames test), micronucleus tests and chromosomal aberration tests. These tests can be performed rapidly and are relatively inexpensive. They are appropriate for estimating the carcinogenic effects of the chemicals and as guidelines for long-term carcinogenicity tests (Kirkland et al., 2006). Such genotoxicity tests have also been modified for detecting antigenotoxicity of natural products (Inboot et al., 2012).

This study aimed at the evaluation of in vitro mutagenicity and antimutagenicity of $C$. nervosum var. paniala extracts by means of the Ames test. Clastogenic and anticlastogenic effects were also observed in rat liver using the micronucleus assay. Because $C$. nervosum is extensively consumed as a fresh fruit, it is desirable to determine the limits of toxicity for large amounts. Acute toxicity test was therefore also assessed in rats.

\section{Materials and methods}

\section{Chemicals}

All chemicals and solvents used were of analytical grade. The standard mutagens used included 2-(2-furyl)-3-(5nitro-2-furyl)-acrylamide (AF-2), 2-aminoanthracene (2-AA), and 2-amino-3,4-dimethylimidazo[4,5- $f]$ quinoline (MeIQ); these were purchased from Wako Pure Chemicals Industries, Ltd. (Osaka, Japan). Aflatoxin B1 (AFB1) was purchased from Sigma Chemical Co. (St. Louis, MO, USA). Cyanidin-3-O-glucoside was purchased from Apin Chemicals Ltd. (Oxfordshire, UK). Collagenase type IV and 4,6-diamidino-2-phenylindole (DAPI) were purchased from Invitrogen Corporation (USA). All solvents used in the analysis of anthocyanin constituents were of HPLC grade.

\section{Plant material}

Ripe fruits of Cleistocalyx nervosum var. paniala were collected during July-August, 2008 from Tambon Choeng Doi, Amphur Doi Saket, Chiang Mai, Thailand. This plant was identified and confirmed by comparing it with voucher specimens of known identities (QBG 7290, QBG 17340, QBG 25139) deposited at the Queen Sirikit Botanic Garden, Chiang Mai, Thailand. The pulp was manually separated from seeds, weighed and stored at $-20^{\circ} \mathrm{C}$ until use.

\section{Sample preparation}

One hundred gram of $C$. nervosum pulp was ground with $50 \mathrm{ml}$ of distilled water using a blender. The mixture was centrifuged at 1,000 g for $15 \mathrm{~min}$ and filtered through a filter paper. The filtrate was dried using a lyophilizer. The aqueous extract was a purplish-red solid with final yield equivalent to $8.48 \mathrm{~g}$.

\section{Determination of total phenolic and flavonoid contents and condensed tannins}

The total phenolic content was determined via the FolinCiocalteu reagent method (Singleton et al., 1999). The absorbance of the sample was measured at $765 \mathrm{~nm}$, and results were expressed as mg gallic acid equivalent (GAE)/g fresh weight $(\mathrm{fw})$. Total flavonoid content was determined using the aluminum chloride colorimetric method. The absorbance at $532 \mathrm{~nm}$ was used and expressed as mg catechin equivalent (CE)/100 g fw (Maksimovic et al., 2005). Finally, the condensed tannin was assessed by the vanillin assay (Butler et al., 1982). After spectrophotometric analysis at $550 \mathrm{~nm}$, the amount of condensed tannins was calculated as $\mathrm{mg} \mathrm{CE} / 100 \mathrm{~g} \mathrm{fw}$.

\section{Quantification of anthocyanins by High-Performance Liquid Chromatography (HPLC) and Liquid Chromatography- Electrospray lonization-Mass Spectrometry (LC-ESI-MS)}

The C. nervosum aqueous extract was dissolved in $0.1 \%$ formic acid in methanol and filtered through filter paper and the remaining methanol was evaporated under reduced pressure.

A $2.1 \times 150 \mathrm{~mm}$ Halo column (Agilent Technologies, USA) with a particle size of $2.7 \mu \mathrm{m}$ was used. The mobile phase consisted of water containing $0.5 \%$ formic acid (solvent A) and methanol (solvent B), with gradient elution started at 85:15 (A:B). The HPLC effluent was passed through the photodiode array detector (PAD), which was set to monitor at wavelengths of 254 and $520 \mathrm{~nm}$. After separation, the HPLC effluent was delivered into a single quadrupole mass spectrometer (Agilent Technologies, USA) via orthogonal atmospheric pressure ionization (API)-electrospray interface. The optimum electrospray ionization (ESI) conditions were as follows: ionization mode, positive; nebulizer pressure, $32 \mathrm{psi}$; drying gas flow rate, $10 \mathrm{~L} / \mathrm{min}$; drying gas temperature, $350^{\circ} \mathrm{C}$; and capillary voltage, 4,000 V. Helium was used as a collision gas and a fragmentor voltage of $130 \mathrm{~V}$ was used for the collision-induced dissociation (CID). The quadrupole temperature was $100^{\circ} \mathrm{C}$ and the electron multiplier voltage was $2,650 \mathrm{~V}$.

The relative contents of anthocyanins in the extract of C. nervosum were obtained by the LC-ESI-MS technique. Naphtholphthalein was used as an internal standard. Peak area normalization was utilized to determine the relative contents of the individual anthocyanin components. Three replicates of sample extract were analyzed.

\section{In vitro mutagenic and antimutagenic assays by Ames test}

Both TA98 and TA100 of Salmonella typhimurium were kindly provided by Dr. Takehiko Nohmi, National 
Institute of Environmental Health Science, Japan. In brief, $20 \mu \mathrm{l}$ of inoculum from the permanent culture were incubated in $10 \mathrm{ml}$ of nutrient broth at $37^{\circ} \mathrm{C}$ for $14 \mathrm{hr}$, until a bacterial concentration of approximately $1.2 \times 10^{9}$ bacterial $/ \mathrm{ml}$ was obtained.

According to the preincubation method described, the Salmonella mutation assay was performed under both non-metabolic and metabolic activation conditions (Maron and Ames, 1983). Briefly, solvent (negative control), $0.8-200 \mathrm{mg} / \mathrm{ml}$ of the extract, or standard mutagens as positive control were added to phosphate buffer or S9 mix. The mixtures were then preincubated with overnight culture of TA98 or TA100 strains at $37^{\circ} \mathrm{C}$ for 20 min before adding a top agar containing $0.5 \mathrm{mM}$ $L$-histidine/ $D$-biotin. In all plates, the $\mathrm{His}^{+}$revertant colonies were analyzed after $37^{\circ} \mathrm{C}$ incubation for $48 \mathrm{hr}$. Triplicate plates per run were assayed.

As mentioned for the mutagenic assay, the preincubation technique was modified in the antimutagenic assay. In brief, the mixtures consisting of solvent alone or $100-200 \mathrm{mg} / \mathrm{ml}$ of extract in the presence of AFB1, MeIQ, or AF-2 were preincubated with overnight culture of TA98 strain with or without $\mathrm{S} 9 \mathrm{mix}$ at $37^{\circ} \mathrm{C}$ for $20 \mathrm{~min}$ before top agar addition. The $\mathrm{His}^{+}$revertant colonies were analyzed after $37^{\circ} \mathrm{C}$ incubation for $48 \mathrm{hr}$. Triplicate plates per run were assayed. The number of counted revertant colonies was subtracted by the number of spontaneous revertants before calculating the percentage inhibition.

\section{Acute toxicity test}

Male and female Wistar rats (150-180 g of weight) were obtained from the National Laboratory Animal Center, Thailand. They were housed under standard environmental conditions at a temperature of $24{ }^{\circ} \mathrm{C}$ under 12 hr dark-light cycle, and allowed free access to drinking water and pelleted diet. The experimental protocol was approved by The Animal Ethics Committee of the Faculty of Medicine, Chiang Mai University.

The acute toxicity of the aqueous extract of C. nervosum was evaluated in rats using the fixed dose procedure (OECD, 2002). Rats were randomly divided into two groups of five animals per each sex. The aqueous extract at a single dose of $5,000 \mathrm{mg} / \mathrm{kg}$ and vehicle was given orally to the treated and control groups. On day 15 , all rats were anesthetized with diethyl ether. The internal organs were excised and weighed. Gross pathological observations of the tissues were performed.

\section{In vivo clastogenic and anticlastogenic assays by rat liver micronucleus test}

Male rats were orally administered $1,000 \mathrm{mg} / \mathrm{kg}$ of $C$. nervosum extract, while the control group was given $5 \%$ tween- 80 as vehicle control for 21 days. All rats were subjected to partial hepatectomy on day 22 . On day 26 , the animals were sacrificed by two-step collagenase perfusion. In brief, anesthetized rats were inserted a canula into the portal vein to infuse the preperfusion medium to remove blood. Second, $0.05 \%$ collagenase medium, pH 7.4 was continuously perfused to isolate hepatocytes.
Third, the liver was incised and then washed with phosphate buffer saline. Finally, the isolated hepatocytes were washed in $10 \%$ buffered formalin and re-suspended in the same solution. Hepatocyte suspensions were mixed with 4',6-diamidino-2-phenylindole dihydrochloride (DAPI) stain solution for fluorescent microscopy. The number of micronucleated hepatocytes was counted and recorded, based on analysis of 2,000 hepatocytes from each animal under a fluorescent microscope. The criteria for micronucleated hepatocyte scoring were described elsewhere (Cliet et al., 1989). Percentages of mitotic index (MI), indicative of mitotic activity, were calculated from mitotic cells in counted hepatocytes.

For the anticlastogenic assay, the protocol used in this study was modified from that described previously (Charoensin et al., 2010). Male rats were divided into 4 groups. The pre- and co-treatments with $100-1,000 \mathrm{mg} /$ $\mathrm{kg}$ of C. nervosum extract concomitant with $30 \mathrm{mg} / \mathrm{kg}$ diethylnitrosamine administration were performed on days 15 and 18. Partial hepatectomy was performed on day 22 and all rats were sacrificed by diethyl ether anesthesia and liver perfusion on day 26 .

\section{Results}

\section{Chemical constituents in an aqueous extract of $C$. nervosum}

The total phenolic compounds were $181.16 \pm 0.59 \mathrm{mg}$ GAE/100 $\mathrm{g}$ fw. The amounts of total flavonoids and condensed tannins were $54.86 \pm 3.45 \mathrm{mg} \mathrm{CE} / 100 \mathrm{~g}$ fw and $1,902.72 \pm 183.63 \mathrm{mg} \mathrm{CE} / 100 \mathrm{~g}$ fresh weight, respectively.

The UV-Vis spectrum measured at $520 \mathrm{~nm}$ of C. nervosum showed three separate peaks at retention times 17.80 , 20.83 , and $42.82 \mathrm{~min}$, which corresponded to anthocyanin constituents. Their LC-ESI-MS spectra indicated the structures consistent with the authentic standards which included cyanidin-3,5-diglucoside, cyanidin-3-glucoside, and cyanidin-5-glucoside, respectively (Figure 1 ). The percentage of relative contents among the assigned anthocyanins indicated that cyanidin-3-glucoside accounted for the major anthocyanin of $C$. nervosum with a relative content of $73.48 \pm 19.26 \%$ (Table 1 ).

\section{In vitro mutagenic and antimutagenic activities of aqueous extract of $C$. nervosum}

For the test doses no killing effect or sign of cytoxicity was observed for either TA98 or TA100 strains of S. typhimurium. The numbers of TA98 and TA100

Table 1. Anthocyanins identified in C. nervosum extract and their relative contents by LC-ESI-MS techniques.

\begin{tabular}{lllccc}
\hline $\begin{array}{l}\text { Retention } \\
\text { time(min) }\end{array}$ & $\begin{array}{c}\text { Structural assignment } \\
\text { of anthocyanins }\end{array}$ & {$[\mathrm{M}]+{ }^{+}$} & $\begin{array}{c}\text { ESI-Mass } \\
\text { spectrum }\end{array}$ & $\begin{array}{c}\text { Relative } \\
\text { Content in } \\
\text { extract (\%) }\end{array}$ \\
\hline 17.80 & cyanidin-3,5-diglucoside & 611 & $287,449,611$ & $0.75 \pm 0.26$ \\
\hline 20.83 & cyanidin-3-glucoside & 449 & 287,449 & $73.48 \pm 19.26$ \\
\hline 42.82 & cyanidin-5-glucoside & 449 & 287,449 & $25.77 \pm 19.01$ \\
\hline
\end{tabular}


A<smiles>OCC1OC(Oc2cc3c(O)cc(O)cc3[o+]c2-c2ccc(O)c(O)c2)C(O)C(O)C1O</smiles>

B

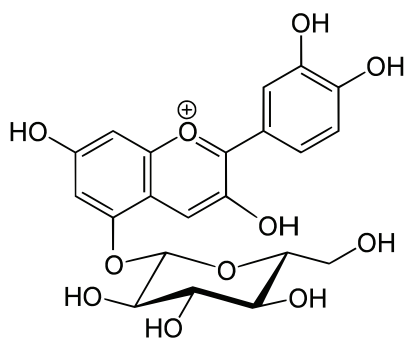

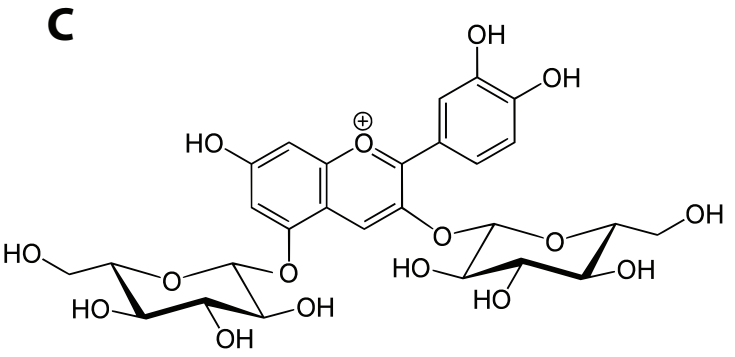

Figure 1. Chemical structures of cyanidin-3-glucoside (A), cyanidin-5-glucoside (B) and cyanidin-3,5-diglucoside (C).

$\mathrm{His}^{+}$revertant colonies from plates treated with $0.8-200 \mathrm{mg} / \mathrm{ml}$ of the extract under present and absent metabolic activation were not significantly different from negative control (Table 2). This suggested that the dose of $0.8-200 \mathrm{mg} / \mathrm{ml}$ of $C$. nervosum extract was non-mutagenic to the strains of S. typhimurium, either with or without metabolic activation. Considering the antimutagenicity of C. nervosum extract in the TA98 strain (Table 3), cotreatment of MeIQ and $100-200 \mathrm{mg} / \mathrm{ml}$ of the extract in the presence of $S 9$ mix showed dose-dependent antimutagenic activity, and the highest dose exhibited significant reduction $(p<0.05)$ of the percentage of revertant colonies (\% inhibition $=62.3 \pm 18.0)$ in comparison with the positive control. However, the percentage of revertant colonies observed from $100-200 \mathrm{mg} / \mathrm{ml}$ of the extract co-treated with AF-2 in the absence of S9 mix was not significantly different from the positive control. The number of revertant colonies by co-incubation of AFB1 with the extract was slightly lower compared with the positive control, indicating a possible weak antimutagenic effect.

\section{Evaluation of acute toxicity of aqueous extract of $C$. nervosum}

None of the animals showed any changes in general appearance after administration of $5,000 \mathrm{mg} / \mathrm{kg}$ of the
Table 2. Mutagenic activity for aqueous extract of $C$. nervosum based on non-metabolic (-S9) and metabolic activation (+S9) using S. typhimurium TA 98 and TA100 strain.

\begin{tabular}{|c|c|c|c|c|}
\hline \multirow[b]{3}{*}{ Treatment } & \multicolumn{4}{|c|}{ Average of $\mathrm{His}^{+}$revertant colonies } \\
\hline & \multicolumn{2}{|c|}{ TA 98} & \multicolumn{2}{|c|}{ TA100 } \\
\hline & $-\$ 9$ & $+\$$ & $-\mathrm{S9}$ & $+\$ 99$ \\
\hline AF-2 $2 \mathrm{ug} / \mathrm{ml}$ & $286 \pm 32.6$ & N.A. & $834 \pm 184.3$ & N.A. \\
\hline 2-AA $10 \mathrm{ug} / \mathrm{ml}$ & N.A. & $408 \pm 35.9$ & N.A. & $612 \pm 186.9$ \\
\hline DW 50 ul & $32 \pm 6.3$ & $37 \pm 9.4$ & $143 \pm 34.8$ & $180 \pm 36.7$ \\
\hline $\begin{array}{l}\text { C. nervosum extract } \\
0.8 \mathrm{mg} / \mathrm{ml}\end{array}$ & $32 \pm 6.1$ & $26 \pm 3.7$ & $138 \pm 39.2$ & $134 \pm 36.1$ \\
\hline $\begin{array}{l}\text { C. nervosum extract } \\
4 \mathrm{mg} / \mathrm{ml}\end{array}$ & $32 \pm 9.0$ & $24 \pm 3.7$ & $137 \pm 41.7$ & $135 \pm 38.0$ \\
\hline $\begin{array}{l}\text { C. nervosum extract } \\
20 \mathrm{mg} / \mathrm{ml}\end{array}$ & $32 \pm 8.8$ & $22 \pm 4.8$ & $133 \pm 31.4$ & $139 \pm 36.6$ \\
\hline $\begin{array}{l}\text { C. nervosum extract } \\
100 \mathrm{mg} / \mathrm{ml}\end{array}$ & $31 \pm 8.0$ & $24 \pm 1.7$ & $141 \pm 44.2$ & $129 \pm 32.2$ \\
\hline $\begin{array}{l}\text { C. nervosum extract } \\
200 \mathrm{mg} / \mathrm{ml}\end{array}$ & $37 \pm 15$ & $30 \pm 9.1$ & N.A. & N.A. \\
\hline
\end{tabular}

The $\mathrm{His}^{+}$revertant colonies are expressed as Mean $\pm \mathrm{SEM}$ of three independent replicates.

AF-2; 2-(2-furyl)-3-(5-nitro-2-furyl)-acrylamide, 2-AA; 2-aminoanthracene, DW; distilled water, N.A.; not analyzed

Table 3. Antimutagenic activity assay for aqueous extract of $C$. nervosum against various mutagens using $S$. typhimurium.

\begin{tabular}{|c|c|c|c|}
\hline \multirow[b]{2}{*}{ Test compounds } & \multicolumn{3}{|c|}{ Average of $\mathrm{His}^{+}$revertant colonies } \\
\hline & $\begin{array}{c}\text { AF-2 } \\
1 \mathrm{ug} / \mathrm{ml}\end{array}$ & $\begin{array}{c}\text { AFB1 } \\
0.16 \mathrm{ug} / \mathrm{ml}\end{array}$ & $\begin{array}{c}\text { MelQ } \\
0.05 \mathrm{ug} / \mathrm{ml}\end{array}$ \\
\hline Standard mutagen & $185 \pm 19.2$ & $428 \pm 75.3$ & $181 \pm 12.9$ \\
\hline $\begin{array}{l}\text { C. nervosum extract } \\
100 \mathrm{mg} / \mathrm{ml}\end{array}$ & $178 \pm 17.5(3.8)$ & $314 \pm 43.7(29.2)$ & $134 \pm 6.0(27.3)$ \\
\hline $\begin{array}{l}\text { C. nervosum extract } \\
150 \mathrm{mg} / \mathrm{ml}\end{array}$ & N.A. & $254 \pm 41.6^{*}(34.1)$ & $69 \pm 3.5^{*}(62.3)$ \\
\hline $\begin{array}{l}\text { C. nervosum extract } \\
200 \mathrm{mg} / \mathrm{ml}\end{array}$ & $142 \pm 14.0(23.8)$ & N.A. & N.A. \\
\hline
\end{tabular}

AF-2; 2-(2-furyl)-3-(5-nitro-2-furyl)-acrylamide, AFB1; aflatoxin B1,

MelQ; 2-amino-3,4-dimethylimidazo[4,5-f]quinoline, DW; distilled water, N.A.; not analyzed

The number of spontaneous revertant colonies range from 17 $\pm 2.4-21 \pm 3.7$. Parentheses indicated the percentage inhibition of the extract against each mutagen.

* Significant difference in comparison with positive control $(p<0.05)$

Table 4. Clastogenicity and anticlastogenicity of an aqueous extract of $C$. nervosum in livers of male wistar rats.

\begin{tabular}{lcc} 
Treatment & MNHEPs/1,000 & Mitotic index (\%) \\
\hline $5 \%$ Tween 80 & $2.15 \pm 1.26$ & $0.15 \pm 0.00$ \\
\hline C. nervosus $1,000 \mathrm{mg} / \mathrm{kg}$ & $2.68 \pm 0.84$ & $0.29 \pm 0.26$ \\
DEN + 5\% Tween 80 & $12.61 \pm 2.05^{*}$ & $0.50 \pm 0.27$ \\
DEN + C. nervosum $100 \mathrm{mg} / \mathrm{kg}$ & $10.17 \pm 3.23$ & $0.45 \pm 0.06$ \\
DEN + C. nervosum $200 \mathrm{mg} / \mathrm{kg}$ & $10.15 \pm 2.05$ & $0.38 \pm 0.17$ \\
DEN + C. nervosum $1,000 \mathrm{mg} / \mathrm{kg}$ & $10.88 \pm 2.79$ & $0.54 \pm 0.41$ \\
\hline
\end{tabular}

MNHEPs $/ 1,000$ (Micronucleated hepatocytes per 1,000 hepatocytes) are expressed as Mean $\pm S D$.

*Significant difference from negative control (5\% Tween 80 as vehicle), $p<0.05$ 
aqueous extract. There were no deaths during the 14-day observation period, and gross examination of internal organs of all rats did not reveal any abnormality.

\section{In vivo clastogenic and anticlastogenic effects of aqueous extract of $C$. nervosum}

The clastogenicity of $C$. nervosum extract was examined by a micronucleus assay in regenerating rat livers. Four days after partial hepatectomy, the growth rate of the treated rats was not significantly different from that of the control group. The mean number of micronucleated hepatocytes and mitotic indices was not significantly different in rats treated with $1,000 \mathrm{mg} / \mathrm{kg}$ of the test compound compared with control rats (Table 4). This suggested that the $C$. nervosum extract was non-mutagenic in rat liver. While the biological activities of anthocyanins from fruits and vegetables have been extensively studied, their anticlastogenicity against diethylnitrosamine (DEN), a hepatocarcinogen in animals and humans, remains unknown. In the present study, the DEN-administered rats had significantly greater numbers of micronuclei and a higher mitotic index compared with control rats. The dosed rats had an average body weight similar to that of the control rats. The analysis of micronucleated hepatocytes of rats administered $100-1,000 \mathrm{mg} / \mathrm{kg}$ of C. nervosum extract showed that the numbers of micronucleated hepatocytes of DEN-treated rats were not affected by any of the doses of the extract tested compared with control rats (Table 4).

\section{Discussion}

Recently, our research group reported the effect of an aqueous extract of $C$. nervosum on antioxidant systems in the rat liver, including total glutathione, glutathione peroxidase, catalase, and heme oxygenase- 1 activities, indicating a possible biphasic effect on oxidative status of the rat liver (Taya et al., 2009). Subsequently, we studied the composition and in vivo biological effects of C. nervosum fruits related to their antioxidant properties. We found that the aqueous extract of $C$. nervosum was rich in cyanidin-3-glucoside with a relative content of $73.48 \pm 19.26 \%$. The LC-ESI-MS spectra indicated that the structures were consistent with the authentic standards and those presented in previous reports, which included cyanidin-3,5-diglucoside, cyanidin-3-glucoside, and cyanidin-5-glucoside, respectively (Figure 1) (Tian et al., 2005; Jansom et al., 2008).

In the studies of in vitro mutagenicity and antimutagenicity, C. nervosum extracts were not only nonmutagenic but also antimutagenic. Co-treatment of MeIQ and the extract in the presence of S9 mix showed dosedependent antimutagenic activity, and the highest dose exhibited significant reduction $(p<0.05)$ of the percentage of revertant colonies in comparison with the positive control. The number of revertant colonies by co-incubation of AFB1 with the extract was slightly different compared with the positive control, indicating a weak antimutagenic effect (Table 3). Anthocyanins and phenolic compounds were reported to exhibit antioxidant, antimutagenic and anticarcinogenic properties (Caillet et al., 2012; Galvano et al., 2004). Our results agree with previous reports in which natural anthocyanins acted as antimutagens. "It has been reported that anthocyanins from colored maize modulate the mutagenic activity of 2-aminoanthracene (2-AA) in S. typhimurium TA98 and TA100 through the inhibition of base-changed mutation (Mendoza-Díaz et al., 2012). Additionally, the anthocyanin colors from vegetables inhibited the reverse mutation induced by food mutagen 2-amino-1-methyl-6-phenylimidazo[4,5-b] pyridine (PhIP) in the presence of rat liver microsomal activation system in a dose dependent manner (Aoki et al., 2004)."

With regard to these findings, the protective activity could be explained as the result of the major anthocyanins. The mechanism of inhibition of the mutagen-activating enzymes is the protection of the hot-spot region of the gene from mutation. Biotransformation of MeIQ and AFB1 are mediated by CYP1A2 and CYP3A4 in human and rat liver cells, respectively (Forrester et al., 1990; Turesky et al., 2002). Therefore, cyanidin glucosides in $C$. nervosum possibly modulate the key enzymes by means of activity inhibition.

While the biological activities of anthocyanins from fruits and vegetables have been extensively reported, their anticlastogenicity against diethylnitrosamine (DEN), a known hepatocarcinogen in animals and humans, has not previously been investigated. We found that DENadministered rats had significantly greater numbers of micronuclei and higher mitotic indices compared with control rats (Table 4). This result was consistent with experiments using DEN as a clastogen inducing hepatic micronuclei in rats and mice (Tates et al., 1980; Cliet et al., 1989). DEN was thus used as a model inducer in the experiment for anticlastogenic activity of $C$. nervosum extract in rat liver. The analysis of micronucleated hepatocytes of rats administered $C$. nervosum extract showed that the extract did not affect the number of micronucleated hepatocytes of DEN-treated rats compared with control rats (Table 4). When consumed, anthocyanins are absorbed in the stomach of rats and appear in both portal and systemic plasma (Passamonti et al., 2003). The anthocyanin concentration of systemic blood may reflect its distribution and existence in target organs, especially the liver as a major site for metabolism. Passamonti et al. proposed a portal blood-liver transport mechanism of anthocyanins, which was related with an organic anion carrier called bilitranslocase in HepG2 cells (Passamonti et al., 2005). They also determined the concentration of anthocyanins in portal and systemic plasma and in liver of rats given a mixture of grape anthocyanins, suggesting that most anthocyanins were absorbed in parent structures. Due to the fact that the in vitro antimutagenic assay used was carried out by bacterial mutation, the biotransformation was not entirely similar to that occurring in test animals. Additionally, the influences of microbial metabolism after upper intestinal absorption and metabolizing enzymes in the liver, along with loss and decrease of bioavailability 
of the active compounds, were possible reasons for the differences in the results from in vitro and in vivo antimutagenic observations.

In conclusion, our results indicated that anthocyanins isolated from the C. nervosum var. paniala fruit were not only safe in acute toxicity test, but even displayed antimutagenicity in vitro. These observations will be beneficial for the development of this species as a medicinal plant.

\section{Acknowledgements}

We gratefully thank Mr. Kitsada Pitija, Ms. Raweewan Somsakchaicharoen and Ms. Wanida Inboot for their technical assistance, and Mrs. Pimwalan Pinthuprapa for supplying C. nervosum fruits. This work was supported by the grants from the Endowment Fund for Medical Research, Faculty of Medicine, Chiang Mai University (1/2553), the National Research Council of Thailand (2010-2011), and Center of Excellence for Innovation in Chemistry, (PERCH-CIC) (2008-2009).

\section{Author disclosure statement: No competing financial} interest exists.

\section{REFERENCES}

Aoki H, Wada K, Kuze N, Ogawa Y and Koda T. (2004). Inhibitory effect of anthocyanin colors on mutagenicity induced by 2-amino-1-methyl-6phenylimidazo[4,5-b]pyridine (PhIP). Foods \& Food Ingred J Jpn 209: 240246.

Butler LG, Price ML and Brotherton JE. (1982). Vanillin assay for proanthocyanidins (condensed tannins): modification of the solvent for estimation of the degree of polymerization. J Agric Food Chem 30: 1087-1089.

Caillet S, Lorenzo G, Côté J, Doyon G, Sylvain JF and Lacroix M. (2012). Cancer chemopreventive effect of fractions from cranberry products. Food Res Int 45: 320-330.

Charoensin S, Punvittayagul C, Pompimon W, Mevatee U and Wongpoomchai R. (2010). Toxicological and clastogenic evaluation of pinocembrin and pinostrobin isolated from Boesenbergia pandurata in Wistar rats. Thai J Toxicol 25: 29-40.

Cliet I, Fournier E, Melcion C and Cordier A. (1989). In vivo micronucleus test using mouse hepatocytes. Mutat Res 216: 321-326.

Dung NT, Kim JM and Kang SC. (2008). Chemical composition, antimicrobial and antioxidant activities of the essential oil and the ethanol extract of Cleistocalyx operculatus (Roxb.) Merr and Perry buds. Food Chem Toxicol 46: 3632-3639.

Forrester LM, Neal GE, Judah DJ, Glancey MJ and Wolf CR. (1990). Evidence for involvement of multiple forms of cytochrome P-450 in aflatoxin B1 metabolism in human liver. Proc Natl Acad Sci USA 87: 8306-8310.

Galvano F, La Fauci L, Lazzarino G, Fogliano V, Ritieni A, Ciappellano S, Battistini NC, Tavazzi B and Galvano G. (2004). Cyanidins: metabolism and biological properties. J Nutr Biochem 15: 2-11.
Inboot W, Taya S, Chailungka A, Meepowpan P and Wongpoomchai W. (2012). Genotoxicity and antigenotoxicity of the methanol extract of Cleistocalyx nervosum var. paniala seed using a Salmonella mutation assay and rat liver micronucleus tests. Mol Cell Toxicol 8: 19-24.

Jansom C, Bhamarapravati S and Itharat A. (2008). Major anthocyanin from ripe berries of Cleistocalyx nervosum var. paniala. Thammasat Med J 8: 364 370.

Kirkland D, Aardema M, Müller L and Hayashi M. (2006). Evaluation of the ability of a battery of three in vitro genotoxicity tests to discriminate rodent carcinogens and non-carcinogens: II. Further analysis of mammalian cell results, relative predictivity and tumour profiles. Mutat Res 608: 29-42.

Maksimovic Z, Malencié D and Kovačević N. (2005). Polyphenol contents and antioxidant activity of Maydis stigma extracts. Bioresource Technol 96: 873877.

Maron DM and Ames BN. (1983). Revised methods for the Salmonella mutagenicity test. Mutat Res 113: 173-215.

Mendoza-Díaz S, Ortiz-Valerio MD, Castaño-Tostado E, Figueroa-Cárdenas JD, Reynoso-Camacho R, Ramos-Gómez M, Campos-Vega R and LoarcaPiña G. (2012). Antioxidant capacity and antimutagenic activity of anthocyanin and carotenoid extracts from nixtamalized pigmented creole maize races (Zea mays L.). Plant Foods Hum Nutr 67: 442-449.

OECD. (2002). OECD Test No. 420: Acute oral toxicity - fixed dose procedure, in: OECD Guidelines for the testing of chemical/section 4: Health effects, pp. 1-14, OECD Publishing, London.

Passamonti S, Vrhovsek U, Vanzo A and Mattivi F. (2003). The stomach as a site for anthocyanins absorption from food. FEBS Lett 544: 210-213.

Passamonti S, Vanzo A, Vrhovsek U, Terdoslavich M, Cocolo A, Decorti G and Mattivi F. (2005). Hepatic uptake of grape anthocyanins and the role of bilitranslocase. Food Res Int 38: 953-960.

Prior RL and Wu X. (2006). Anthocyanins: structural characteristics that result in unique metabolic patterns and biological activities. Free Radic Res $\mathbf{4 0}$ 1014-1028.

Rao KS, Xu Y, Shaw E, and Parton JW. (2004). Mutagenicity testing applied for regulation of developing products. Curr Sep 20: 141-144.

Singleton VL, Orthofer R and Lamuela-Raventós RM. (1999). Analysis of total phenols and other oxidation substrates and antioxidants by means of Folin-Ciocalteu reagent. Meth Enzymol 299: 152-178.

Stoner GD, Wang LS and Casto BC. (2008). Laboratory and clinical studies of cancer chemoprevention by antioxidants in berries. Carcinogenesis $\mathbf{2 9}$ : 1665-1674.

Tates AD, Neuteboom I, Hofker M and den Engelse L. (1980). A micronucleus technique for detecting clastogenic effects of mutagens/carcinogens (DEN, DMN) in hepatocytes of rat liver in vivo. Mutat Res 74: 11-20.

Taya S, Punvittayagul C, Chewonarin T and Wongpoomchai R. (2009). Effect of aqueous extract from Cleistocalyx nervosum on oxidative status in rat liver. Thai J Toxicol 24: 101-105.

Tian Q, Giusti MM, Stoner GD and Schwartz SJ. (2005). Screening for anthocyanins using high-performance liquid chromatography coupled to electrospray ionization tandem mass spectrometry with precursor-ion analysis, product-ion analysis, common-neutral-loss analysis, and selected reaction monitoring. J Chromatogr A 1091: 72-82.

Turesky RJ, Guengerich FP, Guillouzo A and Langouet S. (2002). Metabolism of heterocyclic aromatic amines by human hepatocytes and cytochrome P4501A2. Mutat Res 506-507: 187-195.

Ye CL, Lu YH and Wei DZ. (2004a). Flavonoids from Cleistocalyx operculatus. Phytochemistry 65: 445-447.

Ye CL, Liu JW, Wei DZ, Lu YH and Qian F. (2004b). In vitro anti-tumor activity of $2^{\prime}, 4^{\prime}$-dihydroxy-6'-methoxy-3',5'-dimethylchalcone against six established human cancer cell lines. Pharm Res 50: 505-510. 